\title{
Knowledge, Attitude and Practice towards droplet and airborne isolation precautions amongs dental health care professionals in India
}

\author{
Manish Jain ${ }^{1}$, Leena Sawla ${ }^{2}$, Anmol Mathur ${ }^{3}$, Tarun Nihlani ${ }^{2}$, Uttara Ayair ${ }^{2}$, Duraiswamy Prabu ${ }^{4}$, Suhas \\ Kulkarni $^{5}$
}

\footnotetext{
${ }^{1}$ M.D.S, Department of Preventive and Community Dentistry, Peoples Dental Acadamy, Bhanpur, Bhopal, Madhya Pradesh, India ${ }^{2}$ M.S., Lecturer, Department of E.N.T., Peoples College of Medical Science and Research Centre, Bhanpur, Bhopal, Madhya Pradesh, India

${ }^{3}$ M.D.S., Department of Preventive and Community Dentistry, India

${ }^{4}$ MDS, Associate professor, Department of Preventive \& Community Dentistry, Darshan Dental College and Hospital, Udaipur, Rajasthan, India

${ }^{5}$ MDS, Professor, Department of Preventive \& Community Dentistry, Darshan Dental College and Hospital, Udaipur, Rajasthan, India
}

Correspondence:

Department of Preventive and Community Dentistry, Peoples Dental Acadamy,

Bhanpur, Bhopal, Madhya Pradesh, India 462037

manrescommunity@yahoo.com

Received: 21/04/2009

Accepted: $25 / 03 / 2010$
Jain M, Sawla L, Mathur A, Nihlani T, Ayair U, Prabu D, Kulkarni S. Knowledge, Attitude and Practice towards droplet and airborne isolation precautions amongs dental health care professionals in India. Med Oral Patol Oral Cir Bucal. 2010 Nov 1;15 (6):e957-61.

http://www.medicinaoral.com/medoralfree01/v15i6/medoralv15i6p957.pdf

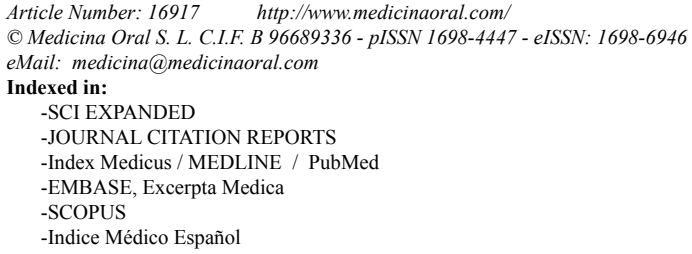

-Indice Médico Español

\begin{abstract}
Aims and Objective- The purpose of this study is to obtain comprehensive information about the knowledge, attitude and practices in regard to droplet and airborne infection related precautions among faculty member and the undergraduate students in Udaipur, Rajasthan, India.

Material and Methods- A cross sectional survey was conducted among 311 dental faculty and the undergraduate students under clinical training in Udaipur, Rajasthan. A self-assessment questionnaire composed of queries on three levels, namely knowledge, attitude and practices with respect to airborne and droplet isolation precautions was used. The data was collected and analyzed by using SPSS software.

Results- Frequency distribution scores of knowledge, attitude and practice in relation to droplet and airborne isolation precautions were revealed that even the students under training along with the faculty member were quite aware of the precautions and the principles of airborne and droplet isolation. Mean score for knowledge was 9.17 \pm 2.07 ; Mean scores for attitude and practice were $48.65 \pm 7.47$ and $6.88 \pm 3.51$ respectively. There were no significant difference in all groups regarding knowledge, attitude and practice. In addition, a positive linear correlation was found between two items of survey including knowledge- attitude, knowledgepractice and attitude- practice $(\mathrm{P}<0.01)$.

Conclusion- The results highlighted that though the professionals had good knowledge and attitude but the practice levels for the same were low. The study confirms from the findings that the infection control measures among the health care professionals are fairly good and an educational programme on isolation precautions can further enhance these levels and thereby, reducing the risk of infection transmission risks.
\end{abstract}

Key words: Knowledge, attitude, practice, isolation, dentists. 


\section{Introduction}

Knowledge, attitude and practice act as three pillars, which make up the dynamic system of life itself. Knowledge is some information that is acquired or gained. It results in congeniality and advertence about an eclectic thing or a situation. There could be many ways of procuring knowledge namely reading, sagacity etc. Knowledge, being the basic criterion that allows one to earmark between the right and the wrong, is a mixture of comprehension, experience, discernment and skill. Attitude accredits to thinking towards an proper situation. There could be a number of furtherance to empathize a situation but it depends on how an individual reacts towards the situation.

Practice means contemplation of rules and knowledge that lead to action. Thus, a right knowledge, a positive attitude and a good practice are imperative to guide and serve the patients.

Dental health care professionals (DHPs) are at a risk of infections caused by various micro- organisms including $\mathrm{M}$. tuberculosis, hepatitis $\mathrm{B}$, hepatitis $\mathrm{C}$ viruses, streptococci, staphylococci, herpes simplex virus type 1, HIV, mumps, influenza, and rubella (1). In a dental office, infections can be expedited through several routes, including direct contact with blood, oral fluids or other secretions; indirect contact with contaminated instruments, operatory equipment or environmental surroundings; or contact with airborne contaminants present in either droplet splatter or aerosols of oral and respiratory fluids (2).

Infected droplets can transmit some diseases by contacting surfaces of eye, nose or mouth. Droplets containing microorganisms can be generated when an infected person sneezes, coughs or talks. Droplets are too large to be airborne for long periods of time, and quickly settle out of air. Oral fluids may become aerosolized during dental treatments and microorganisms from the oral cavity will contribute to the spread of infections. Aerosols are particles less than 5 micrometers in diameter. The smaller particles of aerosols have the potential to penetrate and lodge in small passages of lung are thought to carry the greatest potential for transmitting infections (2). Airborne transposition refers to situations where droplet nuclei or dust particles containing microorganisms can remain pendulant in air for long periods of time. Diseases capable of airborne transmission are influenza, pneumonia, tuberculosis, whooping cough and polio (3-5). The increasing contingency of infection transmission has led to an cognizance of increased of risk of cross infection between patients and dentists; which in turn has brought about a recrudescence regarding infection control during the last decade (6). Infection control practices in developing countries have not been widely indexed. Most of the hospitals have no infection control programmes due to indigence of awareness of problem or penury of atrociously trained personnel's. So a need exists for proper practice of infection control by both dental staff and dental nurses (7).

Centers for disease control and prevention (CDC) have recommended guidelines that include precautions and transmission based isolation precautions that aid in coffer- like working environment and proscribe the transmission of infections (8). The endeavor of this study was to contrive comprehensive information about the knowledge, attitude and practice in regards to droplet and airborne infection precautions among the dental health care professionals, embodying the dental students in Udaipur.

\section{Material and Methods}

- Subjects and sampling

A cross sectional survey was conducted in January, 2009, at Darshan Dental College and Hospital in Udaipur among 350 dental faculty and students (those who had clinical training experience and were enrolled in $3^{\text {rd }}$ or $4^{\text {th }}$ year of undergraduate dentistry programme in Udaipur, Rajasthan). The city of Udaipur is located in Rajasthan, a state in the north- western part of India. Out of the 350 questionnaire forms distributed to various respondents, 311 forms were received. Thirty- seven respondents were MDS, fifty- four were BDS, and the remaining were the students of $3^{\text {rd }}$ and $4^{\text {th }}$ year. There were no statistical differences between responders and non - responders regarding their level of education, sex and mean age.

A visit was made to the faculty and the students and the questionnaire was straggled with exigent instructions for the same. The subjects answered the questionnaire and the data collected was maintained under strict confidentiality.

- Questionnaire design

The questionnaire was designed and the ethical clearance was obtained from the ethical committee of Darshan Dental College and Hospital, Udaipur. The questionnaire comprised of queries on knowledge, attitude and practice of guidelines with respect to airborne and droplet isolation precautions as adumbrated by the CDC.

The content authenticity was pretested on a desultory sample of population to ascertain practicability, cogency and rendition of responses. The knowledge, attitude and practice levels of respondents regarding standard alienation precautions as described by the CDC were appraised using 11 questions for each.

The knowledge was quantified at three possible levels (yes, no, I do not know), and a score value of 
1 was assigned when the answers to questions were in accession with the CDC guidelines. Therefore, the score for knowledge assorted between 0 (all incorrect answers) to 11 (all correct answers). Attitude assessment questions had three levels (very strong, strong and null), where the answers very strong and strong were accustomed 5 points and null received 1 point. Therefore, the total score ranged from 11 (all questions regarded as null) to 55 (all questions regarded as very strong and strong). For practice questions four answer formats of always, often, sometimes and never were used. One point was allotted to the correct and a score of 0 was assigned to all others. The total practice scores ranged from 0 (all incorrect answers) to 11 (all correct answers).

- Statistical analysis

The variables were analyzed on the basis of which were premeditated to be associated with various outcomes of interest. Statistical analysis for knowledge, attitude and practice frequencies together with means and standard deviations (SDs) were calibrated.
Analysis of variance was performed to detect differences of knowledge, attitude and practice between all four groups (MDS, BDS, and the students of $4^{\text {th }}$ and $3^{\text {rd }}$ year) by using SPSS software. Spearman's correlation coefficient was applied to compute the correlation between knowledge and practice, knowledge and attitude and attitude and practice. A twosided $\mathrm{P}$ value of 0.05 was considered monumental for all statistical analysis.

\section{Results}

Response rate was 88.85 ( 311 of 350 ). There were no statistical difference between responders and nonresponders regarding their level of education $(\mathrm{p}=0.4)$, gender $(\mathrm{p}=0.3)$, and mean age $(\mathrm{p}=0.5)$. Out of 311 respondents 37 respondents were MDS, 54 were BDS, and the remaining were the students of $3^{\text {rd }}$ and $4^{\text {th }}$ year.

Table 1 shows the percentage of responses on knowledge, attitude and practice on droplet and airborne precaution. The result of the study revealed that for

Table 1. Frequency distribution of answers regarding knowledge on droplet and airborne precautions.

\begin{tabular}{|c|c|c|c|c|c|c|}
\hline \multirow[t]{2}{*}{ Questions } & \multicolumn{2}{|c|}{ KNOWLEDGE } & \multicolumn{2}{|c|}{ ATTITUDE } & \multicolumn{2}{|c|}{ PRACTICE } \\
\hline & $\begin{array}{l}\text { Correct } \\
\mathrm{N}(\%)\end{array}$ & $\begin{array}{l}\text { Incorrect } \\
\mathrm{N}(\%)\end{array}$ & $\begin{array}{l}\text { Very strong } \\
\text { and strong } \\
\mathrm{N}(\%)\end{array}$ & $\begin{array}{l}\text { Null } \\
\text { Response } \\
\text { N (\%) }\end{array}$ & $\begin{array}{l}\text { Correct } \\
\mathrm{N}(\%)\end{array}$ & $\begin{array}{l}\text { Incorrect } \\
\mathrm{N}(\%)\end{array}$ \\
\hline $\begin{array}{l}\text { Q1.Patients with a droplet spread disease } \\
\text { should be isolated in a private room }\end{array}$ & $265(85.2)$ & $46(14.8)$ & $273(87.8)$ & $38(12.2)$ & 151(48.6) & $160(51.4)$ \\
\hline $\begin{array}{l}\text { Q2.Patients with a droplet spread disease } \\
\text { should be kept at a distance of at least } \\
150 \mathrm{~cm}\end{array}$ & $215(69.1)$ & $96(30.9)$ & $229(73.6)$ & $82(26.4)$ & 104(33.4) & $207(66.6)$ \\
\hline $\begin{array}{l}\text { Q3.Patients with a droplet spread disease } \\
\text { should wear a mask during transport }\end{array}$ & $309(99.4)$ & $2(0.60$ & 295(94.9) & $16(5.1)$ & 281(90.4) & $30(9.6)$ \\
\hline $\begin{array}{l}\text { Q4.Mask should be worn if or when a } \\
\text { subject is within a } 90 \mathrm{~cm} \text { distance from a } \\
\text { patient under droplet precaution care }\end{array}$ & $275(88.4)$ & $36(11.6)$ & $248(79.6)$ & $63(20.3)$ & 192(61.7) & $119(38.3)$ \\
\hline $\begin{array}{l}\text { Q5.Hospital wards should be notified prior } \\
\text { to receiving a patient needing droplet pre- } \\
\text { cautions }\end{array}$ & $299(96.1)$ & $12(3.9)$ & $294(94.5)$ & $17(5.5)$ & $174(55.9)$ & $137(44.1)$ \\
\hline $\begin{array}{l}\text { Q6.Patients with an airborne transmissible } \\
\text { disease should be isolated in a private } \\
\text { room with negative pressure }\end{array}$ & $230(74)$ & $81(26)$ & $203(65.3)$ & $108(34.7)$ & $139(44.7)$ & $172(55.3)$ \\
\hline $\begin{array}{l}\text { Q7.The door of patient's room with an air- } \\
\text { borne transmissible disease should always } \\
\text { be closed }\end{array}$ & $193(62.1)$ & $118(37.9)$ & $288(92.6)$ & $23(7.4)$ & $178(57.2)$ & $133(42.8)$ \\
\hline $\begin{array}{l}\text { Q8.Wearing mask is necessary when enter- } \\
\text { ing room of patients with chickenpox or } \\
\text { measles }\end{array}$ & $212(68.2)$ & $99(31.8)$ & $243(78.1)$ & $68(21.9)$ & $222(71.4)$ & $89(28.6)$ \\
\hline $\begin{array}{l}\text { Q9. All health care workers should be vac- } \\
\text { cinated with B.C.G. vaccine }\end{array}$ & $282(90.7)$ & $29(9.3)$ & 298(95.8) & $13(4.2)$ & $263(84.6)$ & $48(15.4)$ \\
\hline $\begin{array}{l}\text { Q10.Wards should be notified prior to re- } \\
\text { ceiving a patient requiring airborne precau- } \\
\text { tions }\end{array}$ & 293(94.2) & $18(5.8)$ & 293(94.2) & $18(5.8)$ & $228(73.3)$ & $83(26.7)$ \\
\hline $\begin{array}{l}\text { Q11Patients requiring airborne precautions } \\
\text { should wear a surgical mask when being } \\
\text { transported }\end{array}$ & $276(88.7)$ & $35(11.3)$ & 281(90.4) & $30(9.6)$ & $185(59.5)$ & $126(40.5)$ \\
\hline
\end{tabular}


knowledge the frequency of correct answers was lowest for the question number 7 (the door of the patient's room with an airborne transmissible disease should always be closed) and was highest for the question number 3 (Patients with a droplet spread disease should wear a mask during transport). This reveals that the dental professionals were very much aware of the risks of transmissible diseases and thus also applies their knowledge in routine practices.

Results also revealed that for attitude and practice the frequency of correct answer was highest for question number 9 and 3 respectively.

In total we found a linear positive correlation between knowledge and attitude(r- $0.861, \mathrm{P}-0.01)$, attitude and practice ( $\mathrm{r}-0.502, \mathrm{P}-0.01)$ and knowledge and practice( r- 0.467, P-0,01) (Table 2).

Mean score for knowledge was 9.17+ 2.07; Mean scores for attitude and practice were $48.65+7.47$ and $6.88+3.51$ respectively. There were no significant difference in all groups regarding knowledge, attitude and practice. (Fig. 1).

Table 2. Spearman's correlation coefficients between knowledgeattitude (K-A), knowledge- practice (K-P) and attitude- practice (A-P) scores regarding droplet and airborne precautions stratified by subgroups.

\begin{tabular}{|c|c|c|c|c|}
\hline Groups & Subgroups & K-A & K-P & A-P \\
\hline \multirow{2}{*}{ Faculty } & M.D.S. & 0.836 & 0.622 & 0.407 \\
\cline { 2 - 5 } & B.D.S. & 0.799 & 0.624 & 0.566 \\
\hline \multirow{3}{*}{ Dental students } & $4^{\text {th }}$ year & 0.844 & 0.555 & 0.504 \\
\cline { 2 - 5 } & $3^{\text {rd }}$ year & 0.839 & 0.514 & 0.491 \\
\cline { 2 - 5 } & Total & 0.861 & 0.502 & 0.467 \\
\hline
\end{tabular}

$\mathrm{P}=0.01$

M.D.S. $=$ Master in Dental Surgery

B.D.S. $=$ Bachelor of Dental Surgery

\section{Discussion}

This survey describes the knowledge, attitude and behavior of dentists in Udaipur, Rajasthan concerning airborne and droplet isolation precautions. We believe that our results can be generalized to the dental practices in the wider Udaipur community. Our study revealed a good adherence to standard isolation precautions among the dental health care professionals of Udaipur. These results were different from other studies as for example; Mehrdad Askarian, Kamran Mirzaei et al. (2) carried out a similar study among the DHPs in Shiraz, Iran. Their study revealed a poor compliance with airborne and droplet isolation precautions among Iranian professionals. Their study revealed that while the DHPs were quite knowledgeable with respect to the contents of the guidelines, this was not reflected in their practice. Several other similar studies have also been conducted to investigate the infection control knowledge, attitude and practice of DHPs.

In comparison to this, the level of knowledge, attitude and behavior were quite good among the DHPs in Udaipur. The study reveals that even the dental students are quite aware of the risks and the measures taken to prevent the spread of these diseases. The compliance rate was fairly good among the DHPs. When the study was compared between the female and the male DHPs it was found that the female subjects were more aware of the subject in concern.

A study conducted by Askarian M et al. (9) showed that mean score for knowledge was $6.71 \pm 0.99$; score for attitude and practice were $34.99 \pm 4.47$ and $4.97 \pm 2.17$, while in our study it was higher. Mean score for knowledge was 9.17 \pm 2.07 ; Mean scores for attitude and practice were $48.65 \pm 7.47$ and $6.88 \pm 3.51$ respectively.
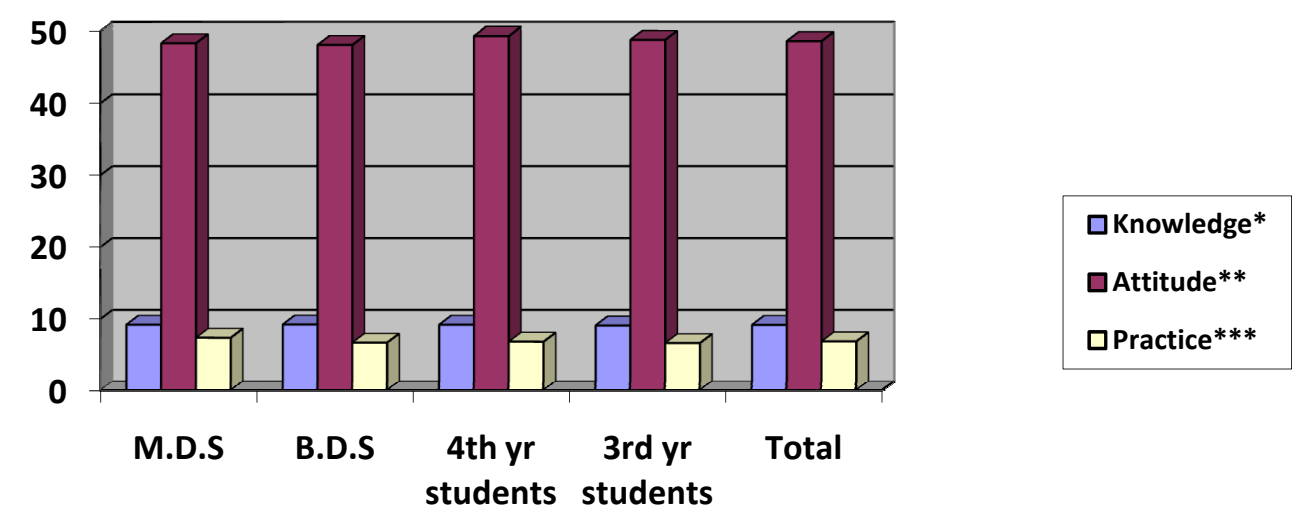

Fig. 1. Mean (SD) of Knowledge*, Attitude** and Practice*** scores regarding droplet and airborne precautions in subgroups at Udaipur, Rajasthan. $\mathrm{F}^{*}-0.062, \mathrm{P} *_{-} 0.980$

$\mathrm{F}^{* *}-0.414, \mathrm{P} * *-0.743$

$\mathrm{F}^{* * *}-0.436, \mathrm{P} * * * 0.728$ 
The little discrepancy might be due to inadequate supply of personal protective equipment, carelessness, improper disposal of medical wastes and the belief that the practice of standard precautions may interfere with patient care $(10,11)$.

Mc Carthy and Mc Donald (12) conducted a similar study in 1997 on general Canadian dentists and found that some predictors of the use of the recommended infection control were age $<40$ years, lack of concern regarding the increased personal risk or cost of infection control procedures. We found that the DHPs in Udaipur, Rajasthan had a good knowledge regarding the isolation precautions.

The high percentage of the correct answers to the questions about potential droplet transmission to patients that are waiting for a dental procedure revealed a good knowledge and practice level.

The universal precaution guidelines determine that chin- length plastics or the surgical masks should be worn when treating the patients due to the splashing or the splattering of the blood or the body fluids (1). The high percentage of correct answers on this issue indicated that knowledge, attitude and practice of the DHPs possibly follow the CDC requirements to prevent the spread of infectious diseases.

One of the limitations of this study was that we could not supervise the responder's practice, so we had to rely on their subjective self- assessment. Therefore, the responses might not have accurately reflected the true levels of knowledge, attitude and behavior, and thus, the reported level of practice might be lower than the real level.

It is important for any hospital or a dental clinic to set up its own measures to prevent the spread of infectious and transmissible diseases. For this purpose, it is important that the dental health care professionals be aware of the risks and the seriousness of infections.

The different aspects of the infection control measures that were assessed in the questionnaire ensured the attainment of specific goals and objective of these measures.

\section{Conclusion}

Survey was conducted to assess the extent of awareness regarding transmissible diseases among the DHPs in Udaipur, Rajasthan. This study also threw a light on the knowledge, attitude and behavior of DHPs and also made them seriously think about the risks that their patients and they themselves face during the treatment procedures. CDC guidelines for isolation precautions were referred to analyze the results of the study. The present study confirms the findings from previous studies that the infection control measures among the DHPs are fairly good.
An educational programmes on infection control isolation precautions for all the health care workers, especially the DHPs and the facilities to allow compliance with the infection policies are necessary to reduce the infection hazards among not only the DHPs but also their patients.

\section{References}

1. Araujo MW, Andreana S. Risk and prevention of transmission of infectious diseases in dentistry. Quintessence Int. 2002;33:376-82. 2. Askarian M, Mirzaei K, Honarvar B, Etminan M, Araujo MW. Knowledge, attitude and practice towards droplet and airborne isolation precautions among dental health care professionals in Shiraz, Iran. J Public Health Dent. 2005;65:43-7.

3. Micik RE, Miller RL, Mazzarella MA, Ryge G. Studies on dental aerobiology. I. Bacterial aerosols generated during dental procedures. J Dent Res. 1969;48:49-56.

4. Miller RL, Micik RE, Abel C, Ryge G. Studies on dental aerobiology. II. Microbial splatter discharged from the oral cavity of dental patients. J Dent Res. 1971;50:621-5.

5. Micik RE, Miller RL, Leong AC. Studies on dental aerobiology. 3. Efficacy of surgical masks in protecting dental personnel from airborne bacterial particles. J Dent Res. 1971;50:626-30.

6. Burke FJ. Use of non-sterile gloves in clinical practice. J Dent. 1990;18:79-89.

7. Qudeimat MA, Farrah RY, Owais AI. Infection control knowledge and practices among dentists and dental nurses at a Jordanian University Teaching Center. Am J Infect Control. 2006;34:218-22.

8. Garner JS. Guideline for isolation precautions in hospitals. Part I. Evolution of isolation practices, Hospital Infection Control Practices Advisory Committee. Am J Infect Control. 1996;24:24-31.

9. Askarian M, Assadian O. Infection control practices among dental professionals in Shiraz Dentistry School, Iran. Arch Iran Med. 2009;12:48-51.

10. Naing L, Nordin R, Musa R. The prevalence of, and factors related to, compliance with glove utilization among nurses in Hospital Universiti Sains Malaysia. Southeast Asian J Trop Med Public Health. 2001;32:636-42.

11. Williams CO, Campbell S, Henry K, Collier P. Variables influencing worker compliance with universal precautions in the emergency department. Am J Infect Control. 1994;22:138-48.

12. McCarthy GM, MacDonald JK. The infection control practices of general dental practitioners. Infect Control Hosp Epidemiol. 1997;18:699-703. 